\title{
New Rigid Backbone Conjugated Organic Polymers with Large Fluorescence Quantum Yields
}

\author{
Andrew P. Davey,* Simon Elliott, Orla O'Connor and Werner Blau \\ Department of Pure and Applied Physics, University of Dublin, Trinity College, Dublin 2, Republic of Ireland
}

The effect on optical emission of the presence of carbon-carbon triple bond linkages in conjugated aromatic copolymers is studied and leads to fluorescence quantum yields of up to $50 \%$, substantially higher than most conventional conjugated polymers.

Since the first demonstration of organic polymer light emitting diodes (polymer LEDs), ${ }^{1}$ materials research in this area has intensified. The main issues to be addressed are device efficiency and material stability. Since the light emitting state in devices appears to be an excited neutral singlet, ${ }^{2}$ the issue of efficiency is very much dependent on the quantum yield of emission of the fluorescent polymers employed. To this end, conjugated polymers with high quantum yields of fluorescence are required.

One approach commonly employed is to limit the delocalisation length of the polymer by interrupting $\pi$-conjugation or synthesising short chain oligomers. ${ }^{3}$ This effectively increases the 'rigidity' of such systems and reduces relaxation from excited states through non-radiative (e.g. thermal) processes. The principal problem with this approach is that limited conjugation leads to lower charge carrier mobility. In general, the lower the carrier mobility, the greater the bias required to drive the device. The ideal material therefore possesses uninterrupted $\pi$-conjugation as well as a high quantum yield of fluorescence.

To date, work has focused primarily on the paraphenylene, ${ }^{4}$ paraphenylene vinylene ${ }^{1}$ and thiophene ${ }^{5}$ families of conjugated polymers. Fluorescence quantum yields for these polymers are typically between $0.1 \%$ and $30 \% .^{7}$ There has been little study of arylene ethynylene polymers, in which aromatic moieties are connected by carbon-carbon triple bonds. 8,9

We have synthesised a series of soluble paraphenylene ethynylene copolymers and measured their quantum yields in solution by comparison with values for previously characterised laser dyes. The general synthetic route to these polymers is illustrated in Scheme 1. The polymerisation method is adapted from that of Giesa. ${ }^{9}$ Polymers 2 and 4 were previously synthesised by this author; however, no comprehensive structural or optical analysis was performed. The yields for this condensation polymerisation are reasonable $(50-100 \%) \dagger$ and give molecular masses ranging from $10 \mathrm{~s}$ to $100 \mathrm{~s}$ of repeat units.

The visible absorption and emission spectra of $\mathbf{3}$ are shown in Fig. 1.\$ The spectra of the samples are all sharp in comparison to other conjugated polymers and are inhomogeneously broadened. The position of the absorption maximum depends on the nature of the co-unit. For small units such as thiophene or pyridine, the maxima are around $450 \mathrm{~nm}$. If a more electron rich unit (such as anthracene) is introduced (e.g. in 4), a significant red-shift of the absorption maximum is observed. Table 1 lists the position of the absorption maxima for the copolymers studied. It is tentatively suggested that the position of the absorption maximum is related to the degree of destabilisation of the HOMO and stabilisation of the LUMO. The presence of the electron-rich anthracene moiety would then serve to reduce the energy gap between these levels and give rise to a red-shift
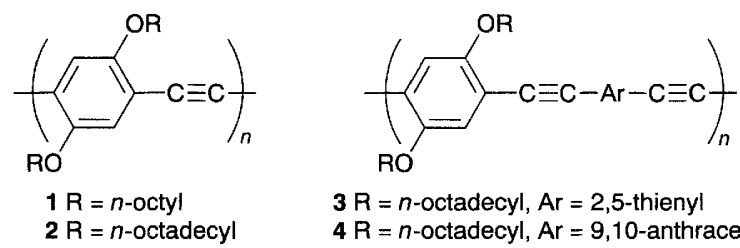

$3 \mathrm{R}=n$-octadecyl, $\mathrm{Ar}=2,5$-thienyl $4 \mathrm{R}=n$-octadecyl, $\mathrm{Ar}=9,10$-anthracenyl $5 \mathrm{R}=n$-octadecyl, $\mathrm{Ar}=2,5$-pyridinyl of the absorption and emission compared to the other polymers.

The fluorescence spectra of the polymers were also recorded. The emission from $\mathbf{3}$ is illustrated in Fig. 1. For all of the polymers studied, the Stokes shift is comparatively small $(<70$ $\mathrm{nm}$ ) indicating a limited degree of coupling to vibrational states in these materials. This is an important point to emphasise since such coupling processes may give rise to excessive heating in LED devices.

The quantum yield of fluorescence from solutions of some of the polymers has been studied by measurement of integrated
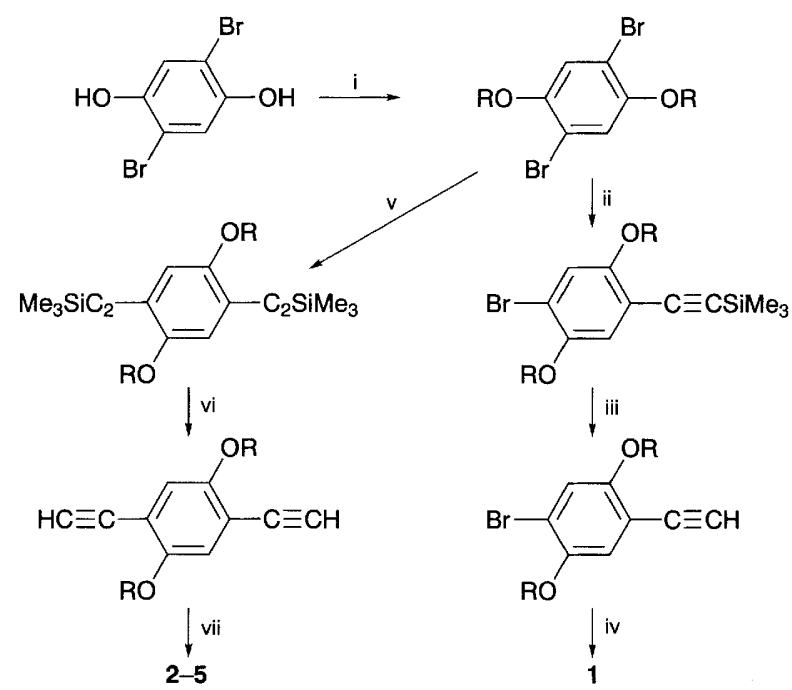

Scheme 1 Reagents and conditions: i, $\mathrm{RBr}, \mathrm{K}_{2} \mathrm{CO}_{3}$, butanone; ii, $\mathrm{Me}_{3} \mathrm{SiC} \equiv \mathrm{CH}$, toluene, $\mathrm{Et}_{3} \mathrm{~N}, \mathrm{Pd}\left(\mathrm{PPh}_{3}\right)_{4}$, CuI, reflux, $24 \mathrm{~h}$; iii, $\mathrm{KOH}, \mathrm{MeOH}$ toluene, reflux, $1 \mathrm{~h}$; iv, toluene, $\mathrm{Et}_{3} \mathrm{~N}, \mathrm{Pd}\left(\mathrm{PPh}_{3}\right)_{4}, \mathrm{CuI}$, reflux, $24 \mathrm{~h} ; \mathrm{v}, 2$ $\mathrm{Me}_{3} \mathrm{SiC} \equiv \mathrm{CH}$, toluene, $\mathrm{Et}_{3} \mathrm{~N}, \mathrm{Pd}\left(\mathrm{PPh}_{3}\right)_{4}, \mathrm{CuI}$, reflux, $12-36 \mathrm{~h} ; \mathrm{vi}, \mathrm{KOH}$ $\mathrm{MeOH}$, toluene, reflux, $1 \mathrm{~h}$; vii, $\mathrm{ArBr}_{2}$, toluene, $\mathrm{Pd}\left(\mathrm{PPh}_{3}\right)_{4}$, CuI, reflux, $24 \mathrm{~h}$

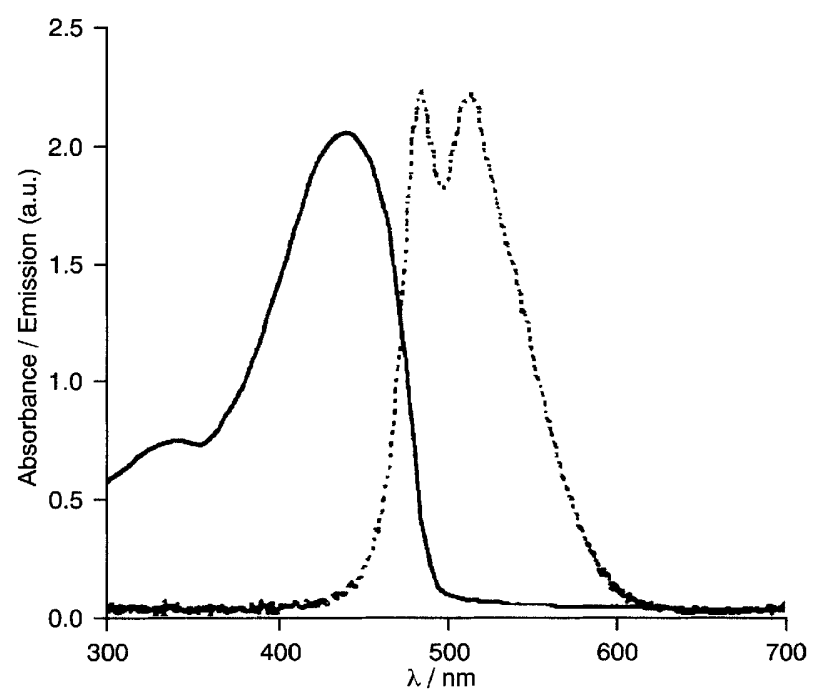

Fig. 1 Electronic absorption (—) and emission $(\cdots)$ spectra of 3 
emission. The quantum yield of a sample in solution $\Phi_{\mathrm{s}}$ relative to a reference sample of known quantum yield $\Phi_{\mathrm{r}}$ may be related by eqn. (1):

$$
\Phi_{\mathrm{s}}=\Phi_{\mathrm{r}}\left(\frac{A_{\mathrm{r}}}{A_{\mathrm{s}}} \times \frac{I_{\mathrm{s}}}{I_{\mathrm{r}}}\right)
$$

where $A_{\mathrm{s}}$ and $A_{\mathrm{r}}$ are the absorbances of the sample and reference solutions respectively at the excitation wavelength; $I_{\mathrm{r}}$ and $I_{\mathrm{s}}$ are the corresponding relative integrated fluorescence intensities. In order to obtain reliable results, it is important to match as closely as possible the optical absorption properties of the sample with those of the reference.

The measured quantum yields of some of the polymers are given in Table 1 . The values are remarkably high in comparison to previously reported values for other conjugated polymers. 6,7 We believe that the smaller quantum yield for $\mathbf{4}$ may be explained in terms of the greater relative moment of inertia of the anthracene moiety favouring non-radiative decay processes. We are currently investigating this by attempting to synthesise polymers with electron-rich co-units with a reduced moment of inertia. This will produce polymers which emit red light with high quantum yields of fluorescence. It should be noted that attempts to determine the fluorescence lifetime of the polymers using time correlated single photon counting have consistently yielded values less than the temporal resolution limit of the instrument ( $c a .1 \mathrm{~ns})$.

To summarise, we have synthesised a family of soluble paraphenylene ethynylene copolymers and characterised their optical absorption and fluorescence properties. Both the absorption and emission maxima are found to vary as a function of the electronic nature of the co-unit, emission colours ranging

Table 1 Quantum yields of fluorescence

\begin{tabular}{lll}
\hline Polymer & $\begin{array}{l}\text { Absorption } \\
\text { maximum/nm }\end{array}$ & $\Phi(\%)$ \\
\hline $\mathbf{1}$ & 415 & $50^{a}$ \\
$\mathbf{2}$ & 425 & - \\
$\mathbf{3}$ & 440 & 45 \\
$\mathbf{4}$ & 580 & 25 \\
$\mathbf{5}$ & 430 & - \\
\hline
\end{tabular}

a Polymer 3 used here as reference: $\Phi$ for 3 was determined by comparison to a $10^{-5} \mathrm{~mol} \mathrm{dm}-3$ solution of Rhodamine $6 \mathrm{G}$ in ethanol, $\Phi$ for 4 was measured by comparison to a $10^{-5} \mathrm{~mol} \mathrm{dm}^{-3}$ Cresyl Violet solution in methanol. from blue through to red. The copolymers exhibit high quantum yields compared to other families of conjugated polymers. It is suggested that this is due to a more rigid conjugated backbone imparted by carbon-carbon triple bond linkages. Initial studies of the polymers in the form of LED devices are promising, strong electroluminescence having been observed from an LED device incorporating 3 .

Received, 22nd March 1995; Com. 5/01830G

\section{Footnotes}

$\dagger$ General procedure: For the synthesis of 3: toluene $(15 \mathrm{ml})$ and triethylamine $(0.5 \mathrm{ml})$ were degassed and to this was added the appropriate phenylene ethynylene compound $(0.5 \mathrm{mmol})$, tetrakis(triphenylphosphine)palladium $(13 \mathrm{mg})$, copper( $\mathrm{I})$ iodide $(3 \mathrm{mg})$ and 2,5-dibromothiophene $(0.5 \mathrm{mmol}, 0.121 \mathrm{~g})$ under Ar. The mixture was refluxed for $18 \mathrm{~h}$. The luminous brown-green solution was then added to methanol $(100 \mathrm{ml})$ and cooled. The resulting solid was filtered, redissolved in toluene, dried $\left(\mathrm{MgSO}_{4}\right)$ and evaporated to a volume of $\mathrm{ca} .20 \mathrm{ml}$. Methanol was added sparingly, the solution was cooled and the precipitated solid collected by filtration to yield platelets of 3 as a brown-red film $(0.275$ g, $0.37 \mathrm{mmol}, 74 \%)$. 'H NMR $\delta 0.88(\mathrm{t}, 3 \mathrm{H}), 1.24-1.92(\mathrm{~m}, 32 \mathrm{H}) .4 .00(\mathrm{t}$, $2 \mathrm{H}), 6.99(\mathrm{~s}, 1 \mathrm{H}), 7.17(\mathrm{~s}, 1 \mathrm{H}) .{ }^{13} \mathrm{C}$ DEPT NMR, $\delta$ 14-32 (Alkyl C 17 ), $69.90\left(\mathrm{OCH}_{2}\right), 88.0(\mathrm{C}=\mathrm{C}), 91.5(\mathrm{C} \equiv \mathrm{C}), 113.9(\mathrm{C}-\mathrm{S}), 116.6(\mathrm{C}=\mathrm{C}-\mathrm{S}), 125.2$ (Aryl CC $\equiv$ ). $132.2($ Aryl $\mathrm{CH}), 153.9\left(\right.$ Aryl $\left.\mathrm{COCH}_{2}\right)$. GPC (Polystyrene standards) $M_{\mathrm{w}}=1 \times 10^{5} ; M_{\mathrm{n}}=6 \times 10^{4}$.

\$ Both spectra were recorded using a $10^{-3} \mathrm{~mol} \mathrm{dm}^{-3}$ solution of 3 in spectroscopic grade toluene.

\section{References}

1 J. H. Burroughs, D. D. C. Bradley, A. R. Brown, R. N. Marks, K. Mackay, R. H. Friend, P. L. Burn and A. B. Holmes, Nature, 1990, 347, 539

2 P. L. Burn, A. B. Holmes, A. Kraft, D. D. C. Bradley, A. R. Brown, R. H. Friend and R. W. Gymer, Nature, 1992, 356, 47.

3 For example, see S. Heun, H. Bassler, U. Muller and K. Mullen, J. Phys. Chem., 1994, 98, 7355 .

4 G. Grem, G. Leditzky, B. Ullrich and G. Leising, Adv. Mater., 1992, 4,

5 N. C. Greenham, A. R. Brown, D. D. C. Bradley and R. H. Friend, Synth. Met., 1993, 55-57, 4134.

6 H. Winkler, A. P. Davey and W. Blau, unpublished results.

7 D. D. C. Bradley, Synth. Met., 1993, 54, 401.

8 T. Yamamoto, M. Takagi, K. Kizu, T. Maruyama, K. Kubota and T. Kaino, J. Chem. Soc., Chem. Commun., 1993, 797.

9 R. Giesa, Ph.D. Thesis, University of Meinz, 1987 